\title{
O Programa de Saúde da Família e os desafios para a formação profissional e a educação continuada
}

\author{
The Family Healthcare Program and the challenges \\ involved in training professionals and continuing education
}

Francisco Eduardo de Campos ${ }^{1}$ Soraya Almeida Belisário ${ }^{2}$

${ }^{3}$ Alguns autores utilizam as

denominações medicina familiar, medicina geral comunitária e medicina de assistência primária como sinônimas.

\footnotetext{
${ }^{1}$ Médico, Doutor em Saúde Pública, Professor Adjunto do Departamento de Medicina Preventiva e Social da Faculdade de Medicina da Universidade Federal de Minas Gerais. <camposfr@medicina.ufmg.br>

${ }_{2}^{2}$ Médica, Professora Assistente do Departamento de Medicina Preventiva e Social da Faculdade de Medicina da Universidade Federal de Minas Gerais. <dadaya@medicina.ufmg.br>
} 


\section{Um pouco de história}

Não é fato novo o surgimento de diferentes projetos de reforma em saúde nos países ocidentais, os quais têm na educação médica um dos seus principais enfoques. Dentre eles, a "Medicina de Família" apresentou-se nos anos setenta como mais um projeto de reforma da prática médica.

Vista como uma alternativa à possível e progressiva desumanização da medicina, este movimento, que se originou nos EUA nos anos sessenta e foi posteriormente reconhecido como especialidade naquele país, expandiu-se nos anos setenta para outros países. Apresentou-se como uma resposta contra o especialismo, justificando-se pelo aumento da complexidade tecnológica da medicina, da tendência à hospitalização e à especialização, dos valores sociais e dos padrões de exercício profissional que aumentavam a demanda por serviços especializados.

A importância do tema pode ser demonstrada por sua inclusão na 92 ${ }^{a}$.Sessão do Comitê Executivo da Organização Pan-Americana de Saúde (OPS), em 1984, quando se apresenta um resumo da situação da medicina familiar na região das Américas (PAHO, 1984).

Os adeptos dessa formação acreditavam que em muitos países havia uma nítida separação entre o sistema de formação médica $e$ as necessidades dos sistemas de saúde, propondo a formação terminal do médico na graduação o médico geral, ou, sinonimamente, o médico de família, atribuindo-se à pósgraduação a tarefa da especialização. No programa educacional do médico de família era preciso prever sua educação continuada, suas condições de trabalho, sua preferência de absorção pelo mercado de trabalho e as boas condições financeiras e de estabilidade (Candau,1988).

Data de 1973 a primeira tentativa de introdução dessa proposta no Brasil, por uma iniciativa capitaneada pela Organização Mundial de Saúde (OMS) e a Associação Brasileira de Ensino Médico (ABEM) que promoveram um seminário na Faculdade de Medicina de Petrópolis, intitulado "A Formação do Médico de Família". Vem a seguir, como marco desencadeador desse processo na América Latina, um seminário realizado em Campinas em 1978, sobre a formação do médico generalista (uma "camuflagem" da expressão médico de família). Colocou-se, nesse momento, a preocupação de se discutir as diferenças existentes entre os diversos projetos em curso saúde comunitária, medicina social, sanitarismo, preventivismo etc., e os programas do médico de família, no intuito de equilibrar a formação do mesmo.

Esta proposta ganhou adeptos, estabeleceu alianças, mas, também, conviveu com opositores. Um balanço geral confirma que foi um movimento muito débil: em duas décadas de existência, as residências de medicina geral/ comunitária/saúde da família não formaram mais que poucas centenas de profissionais e ficaram circunscritas a poucas unidades federadas. Houve enfrentamentos com outras correntes institucionalizadas e resistências à expressão "médico de família". A resistência se deu, mormente, pelo rechaço à idéia de que se segmentasse a assistência, sendo os cidadãos de primeira assistidos pelo especialistas e os pobres pelos médicos de família, como acontecia em vários países. Outro importante argumento dizia respeito ao 
${ }^{4}$ Institucionalização da Residência em Medicina de Família através da Resolução 07/81 com o nome de Medicina Geral Comunitária. Para ABATH (1985, p.50-1) "a expressão medicina familiar encontra, às vezes, uma certa resistência de caráter ideológico, preconceitual..."

Afirma, ainda, ser a expressão medicina geral comunitária a mais aceita para expressar "a prática desenvolvida pelo médico geral, generalista, ou médico de família". risco que a adoção da proposta poderia trazer à terminalidade dos cursos de graduação: o que faria com que as destrezas e habilidades, que não haviam sido logradas em seis anos, o fossem em dois anos subseqüentes e qual seria o destino daqueles que não conseguissem sequer o acesso a essa especialidade? O que diferenciava o médico de família daquele bem formado na graduação? Era essa uma proposta de remendo às precariedades dos cursos médicos? Neste caso, não seria melhor reformar a graduação, evitando-se os remendos posteriores?

Várias tentativas de implantação da proposta foram feitas, as quais conviveram lado a lado com embates nos planos político e ideológico. Nesse processo observou-se, em sua estratégia de implantação, a predominância de uma tônica racionalizadora, que preconizava a reorganização dos serviços de saúde devido aos altos custos na sua produção; à imposição de uma redefinição do conceito do médico de família; à atuação política da Comissão Nacional de Residência Médica (CNRM) ${ }^{4}$, tentando impor a adoção desta proposta e a tentativa de se estabelecer o Instituto Nacional de Assistência Médica da Previdência Social (INAMPS) como um possível interessado no perfil do médico de família, sendo seu potencial empregador.

Contudo, o movimento de transformação e crítica do setor saúde, já em curso, caminhava em direção a uma perspectiva mais avançada.

Verificou-se que a proposta prática da medicina familiar era inconsistente com a orientação teórico-metodológica alcançada pela Medicina Preventiva $e$ Social (MPS) e com as tendências, em curso, da política de saúde no Brasil, ao mesmo tempo em que os pressupostos da Medicina de Família (MF) se chocavam com a tendência racionalizadora da Saúde Coletiva (SC) e com a vertente crítica da Medicina Social (Paim, 1986).

Por sua vez, as expectativas relativas ao mercado de trabalho não se concretizaram uma vez que o INAMPS não absorveu os profissionais egressos dos cursos de pós-graduação, o mesmo ocorrendo em relação aos estados e municípios.

Este processo, com suas denominações e roupagens diversas, foi caracterizado por Paim (1986) como

\footnotetext{
mais um movimento ideológico visando responder aos impasses e questionamentos sobre o modelo dominante de atenção médica, sobretudo no que se refere aos altos custos, sofisticação e super especialização do cuidado. Todavia, enquanto movimento de reforma médica apresenta-se empobrecido conceitualmente quando comparado com outros que lhe precederam tais como a Medicina Preventiva e a Medicina Comunitária. As perspectivas de mudança por ele evocadas, conseguem ser mais parciais e incompletas que as propostas pela Medicina comunitária. (Paim, 1986, p.21-2)
}

Acredita também esse autor que "o movimento da Medicina de Família não parece ter contribuído para uma aproximação crítica em relação à tese da inadequação da educação médica. Pelo contrário, suas concepções mascaram os determinantes da crise da educação médica e insinuam soluções descoladas dessa mesma realidade" (Paim,1986, p.23). 
A criação do Sistema único de Saúde (SUS), reconhecendo o direito universal à saúde e priorizando a atenção primária, passa a exigir opções mais efetivas, visando a implementação de um modelo integral capaz de ser resolutivo em todos os níveis de atenção.

\section{A especificidade da Reforma Sanitária brasileira}

Nas últimas décadas, um grande número de países no mundo, entre eles a quase totalidade dos países da América, impulsionou várias modalidades de reformas no setor saúde.

Nos países latino-americanos observa-se que a tônica do processo de reforma do setor saúde está calcada em propostas levadas a efeito pelos organismos internacionais de fomento, estando sempre presentes a redução do papel do Estado à sua função reguladora e a separação entre financiamento e provisão.

O caso brasileiro está distante desta tendência geral e guarda uma característica muito própria, provavelmente porque representa mais um movimento de dentro para fora que o oposto, distinto e divergente dos demais modelos em muitas de suas características. A tendência inclusionista, já vivenciada desde o início da Previdência Social, havia criado um vetor em que cada dia mais cidadãos passaram a ter, pelo menos no campo formal, garantias de direitos. Não representa surpresa, portanto, a inscrição, na constituição, dos princípios da universalidade, eqüidade e integralidade que presidem a lógica e os movimentos do SUS, dando a diferença entre o que ocorre no Brasil em relação aos demais países.

Os ideólogos da reforma sanitária brasileira, imbuídos dos conceitos básicos do planejamento estratégico-situacional, criaram um cenário onde idéias que avançassem o sistema pudessem prevalecer. Além de idéias academicamente bem trabalhadas, foi criado um novo arco de alianças, que incluía um novo ator, até então ausente - o usuário, conferindo autosustentabilidade a este movimento. A partir de então, avanços na estruturação de um novo arcabouço institucional se fizeram notar, em que pese a enorme entropia das poderosas instituições então existentes. Um processo de descentralização ímpar, efetivo e inimaginável quinze anos atrás e um avanço do controle social, fora até mesmo de qualquer perspectiva de controle burocrático pelos seus propositores. Ficara como questão pendente o asseguramento de níveis estáveis de financiamento que pudessem fazer o SUS cumprir seu desiderato. A opção correta, sob o ponto de vista teórico, de incluir saúde no capítulo constitucional da seguridade social, criou um grave problema pela crise do sistema previdenciário, que fustigou sem trégua a saúde. Ainda, este problema encontrou, não sem muita luta $e$ persistência, um encaminhamento satisfatório, visto que um amplo arco de alianças criou uma emenda constitucional para estabilizar o financiamento. O correto encaminhamento das questões anteriores foi necessário, porém, não suficiente para proporcionar avanços na saúde da forma que se imaginava. Não houve a percepção, contudo, de que estas questões macro, isoladamente, deveriam se conjugar às micro, ou seja, a proposição de um modelo assistencial. A própria lei 8080 , que regulamenta o SUS, avança 
${ }^{5}$ É vastíssima a bibliografia acerca da proposta dos Sistemas Locais de Saúde tanto de lavra da Organização Pan Americana da Saúde quanto de seus países membros.
${ }^{6}$ Tome-se em conta que a experiência de muitos países latino americanos, onde foi implantada a proposta dos pacotes básicos $e$ da focalização, a reforma parou aí: em nenhum caso surgiu a necessidade do equacionamento dos demais níveis de complexidade por exigência dos usuários. pouco no que poderia ser o "modelo", referindo-se vagamente às idéias da regionalização e hierarquização. O trecho que mais se aproxima do que seria a organização do modelo é o artigo 10 que afirma: "No nível municipal, o Sistema Único de Saúde (SUS), poderá organizar-se em distritos de forma a integrar e articular recursos, técnicas e práticas voltadas para a cobertura total das ações de saúde." (grifo nosso)

Ou seja, essa é uma vaga indicação de uma forma débil de organizar o sistema de atenção. O máximo que se fez, nestes tempos iniciais, foi trabalhar um vago conceito de distrito sanitário, tão anódino quanto seu equivalente latino-americano, o dos Sistemas Locais de Saúde (SILOS)5. Esta última proposta, flagship das propostas da OPAS de uma década atrás, praticamente desapareceu do dicionário da organização nos últimos cinco anos, por problemas similares.

A vitória eleitoral de forças retrógradas no início da década de noventa promove um relativo arrefecimento da Reforma Sanitária. A persistência de condições de existência social ainda muito precárias faz ter início, no nordeste brasileiro, uma importante experimentação social, que foi a implantação do Programa dos Agentes Comunitários de Saúde (PACS). Não se trata de novidade, uma vez que, em 1970, todo o país assistira à experiência da capacitação dos auxiliares de saúde, inicialmente no Norte de Minas e, posteriormente, no Programa de Interiorização de Ações de Saúde e Saneamento (PIASS). A diferença foi a intensidade do apoio a esta iniciativa $e$ a visibilidade que adquiriram seus resultados, exatamente por incidirem sobre populações muito postergadas.

A despeito de um sem número de críticas - chegou-se mesmo a suspeitar que essa seria uma política alternativa ao SUS e à ressurreição da medicina de pobres para miseráveis -, o impacto que teve essa proposta, relativamente simples e de baixo custo, demonstrou sua viabilidade e abriu caminhos para a proposta de Saúde da Família. Em outro contexto, em que a politização da saúde não fosse tão marcante, certamente a experiência poderia ter parado aí. Provavelmente, é a mobilização social em torno da saúde que, ao reafirmar o princípio da eqüidade, impõe a necessidade de busca de soluções institucionais para a referência e a contra-referência daqueles problemas impossíveis de serem solucionados pela ação isolada dos agentes ${ }^{6}$. No caso brasileiro, seria impossível um retrocesso que aceitasse solução "rasa" aos problemas dos setores mais carentes $e$, daí, surge a incorporação do PSF como uma continuidade e um aperfeiçoamento do PACS. De seus primeiros passos até a "contaminação" do conjunto do país, tudo se passou num movimento de constante crescimento. A existência de mais de dez mil equipes implantadas ao tempo em que esta reflexão é escrita, a recente incorporação da atenção à saúde oral e a existência de mais de um milhão de agentes comunitários de saúde no país dão a cabal demonstração da magnitude dessa proposta, ainda que não se constitua em automática garantia de sua continuidade.

Aconteceu neste movimento um fato insólito: sem que a "intelligentzia" da reforma sanitária tivesse planejado, o PSF abriu a possibilidade de ruptura da lógica que presidira a produção dos serviços de saúde desde os tempos dos institutos e do INAMPS, e que seguia atravessada na garganta 
dos reformadores, que era a lógica do pagamento ou do repasse financeiro atrelada à produção de serviços.

Se o PSF não representava mais a medicina dos excluídos, abria-se a possibilidade de humanização e responsabilização, não havia mais porque manter a guarda ideológica contra a proposta, e, por tal razão, pouco a pouco, os círculos do "partido sanitário" passaram a aderir à mesma. Seria insensato afirmar que este profundo processo de mudanças se deu suavemente. Ao contrário, à medida que o governo federal passou a incentivá-lo financeiramente, surgiu o risco de uma implantação pró-forma, apenas para receber os incentivos, bem como os favorecimentos políticos feitos aqui $e$ ali.

Também no plano internacional, a discussão sobre o médico de família ganha enorme relevância. Vale citar, a este respeito, a Conferência "A contribuição do médico de família”, realizada em Ontario, Canadá, em 1994, patrocinada pela Organização Mundial de Saúde (OMS) e pela Organização Mundial dos Médicos de Família (WONCA) (WHO, 1994).

Compartilhando de uma mesma visão, num processo de cooperação considerado por ambos como histórico, estes organismos apontaram a necessidade de mudanças fundamentais tanto nos sistemas de saúde, na profissão e nas escolas médicas, como também em outras instituições educacionais, para que se pudesse atender às necessidades da população.

Apontaram, também, o papel central do médico da família, sua competência e capacidade de integrar o cuidado individual com o da comunidade no alcance da qualidade, do custo-efetividade e eqüidade nos sistemas de saúde.

Conclamaram os formuladores de políticas, as organizações de saúde, os líderes da educação médica e os representantes das associações profissionais e da comunidade, a compartilhar essa visão e estabelecer relações de cooperação e trabalho no sentido de alcançar o objetivo de "saúde para todos".

A introdução da equipe num processo de trabalho multiprofissional, a comunidade como referência, a criação de um mercado, sua diretriz política e suas dimensões, conferem elementos diferenciadores a esta proposta. A partir do momento em que a proposta do PSF se identifica com os elementos axiomáticos da reforma sanitária brasileira, surge a percepção de que não se pode apenas criticá-la como se ela fosse a reprodução dos pacotes básicos, mas se faz uma mudança de posição que possa, inclusive, interferir em sua condução.

Entre os distintos problemas que afloram com a implantação do PSF nenhum é mais grave que a carência de profissionais em termos quantitativos e qualitativos para atender a esta nova necessidade. Contudo, todos estes elementos só fazem aprofundar o desafio ao se discutir o processo de formação e educação continuada destes profissionais, agora organizados em forma de equipe.

Em pauta, estão colocadas algumas modalidades de formação como o Curso de Especialização em Saúde da Família, dirigido a profissionais de nível superior; as propostas de capacitação da equipe em conjunto e a criação de residências multiprofissionais em Saúde da Família. A escola médica e a 
(im)possibilidade da formação terminal, ainda se apresentam como desafios.

A encruzilhada da educação médica: buscando o elo perdido

O progresso científico e tecnológico ocorrido nos últimos anos e sua incidência sobre a prática médica foram responsáveis pelo descortino de horizontes impensáveis e por efetivar possibilidades, também impensáveis, de solução dos problemas de saúde. Como contrapartida, assistiu-se à segmentação $e$ ao inusitado aumento da complexidade da assistência à saúde. Certamente, a raiz deste processo encontra-se na autohomogeneização promovida pela medicina norte-americana no início deste século, que teve como seu momento mais marcante a publicação e a consecução das recomendações do relatório Flexner.

A segmentação da prática $e$ a incorporação tecnológica desenvolveram-se de forma exponencial a ponto de gerar uma crise de financiamento que atingiu não apenas os países pobres, mas todos os quadrantes do planeta. Um dos resultados da segmentação do cuidado e da crescente especialização foi a perda do elo ontológico que estabelecia a relação entre médico $e$ paciente baseada não apenas na técnica, mas em todo um processo comunicativo e de conhecimento que transcendia o puro e simples ato de intervir e prescrever.

Sucessivos movimentos internacionais - vale citar aí o Relatório Lalonde, a Reunião de Alma Ata, a proposta de Saúde para Todos, o movimento de Promoção da Saúde - tentam contrarrestar essa tendência, seja para fazer a atenção à saúde acessível a todos, seja para humanizar a prática médica, restabelecendo, assim, o antigo elo de confiança, alicerce da prática médica.

Num contexto em que os mecanismos de comunicação tiveram desenvolvimento meteórico e, no que tange à educação médica, a avassaladora dupla progresso técnico/segmentação teve, ao lado de efeitos benéficos, efeitos colaterais, que se podem citar:

- evidenciou-se uma enorme lacuna entre as instituições acadêmicas do primeiro mundo e as demais;

- houve um alongamento temporal da formação médica, causado pela própria divisão do mercado especializado. Com isso, o foco do processo formativo deslocou-se, paulatinamente, da graduação para a pós-graduação. Uma vez que os egressos buscam um mercado educacional ao invés de um mercado de trabalho, a terminalidade deixa de ser preocupação e a tendência a que se transformem em uma função ritualística e protelatória se instala. Razão adicional é a própria concepção do que seja a missão das escolas médicas. Em momentos anteriores, seria razoável aceitar-se a idéia de que a Escola terminava sua missão ao diplomar seus alunos. Isso se deu num tempo em que existia uma relativa estabilidade dos conhecimentos e a obsolescência dos mesmos não se dava como ocorre hoje. Mais que nunca é preciso estar atento ao fato de que grande parte dos conhecimentos $e$ técnicas, recomendáveis hoje, estará em desuso dentro de uma década, $e$ que, portanto, mais importante que transmitir conhecimento, é criar hábitos e métodos que valorizem o auto-aprendizado, a abordagem crítica dos conhecimentos e a permanente inquietação; 
- o avanço tecnológico que revolucionou a prática médica tem o mesmo potencial de incidir sobre a educação médica, por diversas razões. A mudança nos perfis de mortalidade torna indisponíveis cadáveres; os grupos ecológicos exigem que não se maltratem os animais; os pacientes não estão mais dispostos a servir de cobaias de repetitivos e desgastantes processos de ensino aprendizagem, o que obriga as principais casas de ensino do mundo a utilizarem pacientes simulados. Ao mesmo tempo, aumenta a oferta de softwares educativos de grande qualidade, que têm o potencial de superar as técnicas convencionais de ensino. $\mathrm{O}$ acesso à informação bibliográfica torna disponível, nas residências dos estudantes, acervos superiores às combalidas bibliotecas das escolas de terceiro mundo. Poder-se-ia antever a clara possibilidade da oferta virtual de cursos de medicina, com qualidade técnica não inferior à média dos oferecidos hoje;

- a segmentação social das práticas assistenciais e também dos usuários dos serviços de saúde abre o mercado a um conjunto de instituições nosocomiais muito sofisticadas, dedicadas, em sua maioria, ao atendimento dos clientes remanescentes das práticas liberais-autônomas ou de contratantes de seguros-saúde de elite. Tais instituições concentram os mais competentes profissionais, muitos dos quais docentes, e a partir daí passam a assumir papel substitutivo ao que foram as escolas médicas no passado: instituições de referência, aquelas que legitimam as "boas práticas" $e$ dão o tom do que é aceitável como referência na assistência à saúde.

Ao mesmo tempo que isso acontece, ganha força no mundo a idéia de revisão do paradigma assistencial, pelo fato de ser desconcertante $e$, por vezes, eticamente inaceitável, a permanência de tamanhas diferenças, conseqüências deste modelo segmentador. O crescimento explosivo dos custos passa a ser um ônus até para as camadas mais abastadas da sociedade. Não casualmente, surgem dentro das próprias administradoras de planos de saúde a convicção de que é necessário estimular estilos saudáveis de vida; propostas como a saúde familiar são impulsionadas; revigora-se a idéia da atenção básica como porta de entrada para os demais níveis assistenciais. Neste contexto, os próprios países centrais, convencidos da insustentabilidade do paradigma anterior, propõem a revisão dos mixes de especialistas/generalistas, ganhando redobrada atenção a formação dos profissionais de enfermagem, entre outros. Os Estados Unidos assistem, pela primeira vez, à diminuição dos diferenciais salariais entre especialistas $e$ generalistas que, apesar de não se terem igualado, têm uma tendência, a médio prazo, de serem menos díspares que o foram no passado.

Todos os fatores apontados neste panorama levam a crer que as escolas médicas se encontram diante de uma decisiva encruzilhada. A prevalecer este modelo, podem elas se diferenciar - algumas formarão pesquisadores, outras especialistas e outras médicos gerais. Em alguns países latinoamericanos já se assiste à abertura de escolas médicas para atender a demandas especiais da elite, de confissões religiosas e de segmentos étnicos determinados. Não se afasta a hipótese de que os próprios seguros-saúde se apropriem de escolas para prepararem profissionais mais acordes à sua perspectiva de acumulação de capital. Certamente, neste caso, persistirá a tendência de privilégio à pós-graduação, dado que é onerosa a formação

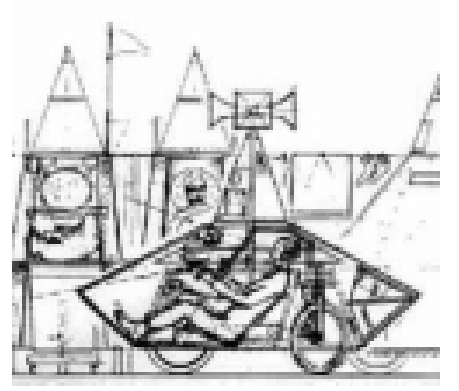


graduada. Perderá sentido a manutenção do juramento hipocrático, que se centra na idéia de que a prática médica beneficie tão somente ao paciente e ao médico.

Existe, entretanto, outra hipótese, na qual muitos de nós, incorrigíveis otimistas, apostamos: que há, mais que nunca, um nicho para que as escolas possam exercer um papel indelegável. Isso significa o reencontro do elo perdido, o de uma medicina humanizada, que alie uma sólida formação ética com elevado compromisso social por parte de seus egressos. Ninguém terá mais autoridade para pregar a possibilidade de se manter a relevância social sem abrir mão da excelência técnica. Para tanto, faz-se necessário promover um profundo processo de mudança, que alce os estudantes à condição de sujeitos do processo de aprendizagem, que tome como ambientes de prática a comunidade, o domicílio, a rede básica do SUS, que possa promover um real entendimento daquilo que causa sofrimento e morte.

Vem se evidenciando que um dos principais óbices à consecução dos relevantes objetivos de se reestruturar o modelo assistencial, com o privilégio de uma atenção básica resolutiva e oportuna, é a formação médica. Os profissionais disponíveis são ainda preparados dentro de uma concepção que privilegia a abordagem individual, curativa e centrada no hospital. São, portanto, incapazes de transcender o espaço do consultório médico e propor diagnóstico e intervenções sobre o coletivo, numa abordagem integralizadora, sem a qual dificilmente se lograrão avanços significativos.

Há uma crise multifacetada atingindo a educação médica, que pode ser entendida pela mudança do mercado de trabalho (as oportunidades de emprego no PSF são consideráveis), pela crise de financiamento da educação superior, pela incorporação tecnológica que faz possível a informação $e$ softwares educacionais $e$, mais recentemente, pela adoção de vários processos de avaliação: acreditação institucional, certificação e recertificação profissionais estão na ordem do dia. Provão, CINAEM, avaliação das condições de oferta, novas diretrizes curriculares, a possibilidade de cursos seqüenciais fazem parte deste novo cenário.

Nunca houve a conjugação de tantos estímulos intrínsecos e extrínsecos a um processo de mudança. A capitalização deste momento para promover, de fato, uma mudança corajosa, seria extremamente oportuna. Valendo-se da prerrogativa constitucional de "ordenar a formação de recursos humanos", o Ministério da Saúde (MS) e os demais gestores do SUS podem exercer papel de vanguarda, propondo estímulo concreto à mudança. Este processo de mudança deveria ter características que vêm sendo longamente trabalhadas por vários grupos dentro do MS. É hoje consensual que a mudança deva incluir a interdisciplinaridade, a mudança dos cenários, nos quais se realizam a ação educativa, para locais mais representativos da realidade sanitária e social, a integração ensino-serviço-pesquisa, a abordagem problematizadora, a educação permanente e o compromisso ético, humanístico e social com o trabalho multiprofissional. 


\section{Referências Bibliográficas}

CANDAU, M. G. Planejamento geral e aspectos doutrinários da formação do médico de família e suas relações com o sistema de saúde. In: CONGRESSO BRASILEIRO DE EDUCAÇÃO MÉDICA, 16, Londrina, 1978.

PAIM, J. S. Medicina familiar no Brasil: movimento ideológico e ação política. In: ABRASCO. Estudos de saúde coletiva. Rio de Janeiro: ABRASCO,1986. p.11-25

PAN AMERICAN HEALTH ORGANIZATION. Status of family medicine in the Americas. In: Meeting of the Executive Committee of the Directing Council, 92, 1984, Washington. Complete collection of documents. Washington: PAHO, 1984. p.23 (CE92/17 En).

WORLD HEALTH ORGANIZATION. WORLD ORGANIZATION OF FAMILY DOCTORS. The contribution of the family doctor (Conference). Ontario, 1994.

PALAVRAS-CHAVE: Saúde da Família; serviços de Saúde; inovação organizacional; administração e planejamento em saúde; saúde pública; educação médica; educação continuada.

KEY WORDS: Family health; health services; organizational innovation; health administration and planning; public health; medical education; continuing education.

PALABRAS CLAVE: Salud de la familia; servicios de salud; innovación organizacional; administración y planificación en salud; salud publica; educación medica; educación continua.

Recebido para publicação em: 21/03/01. Aprovado para publicação em: 11/04/01.

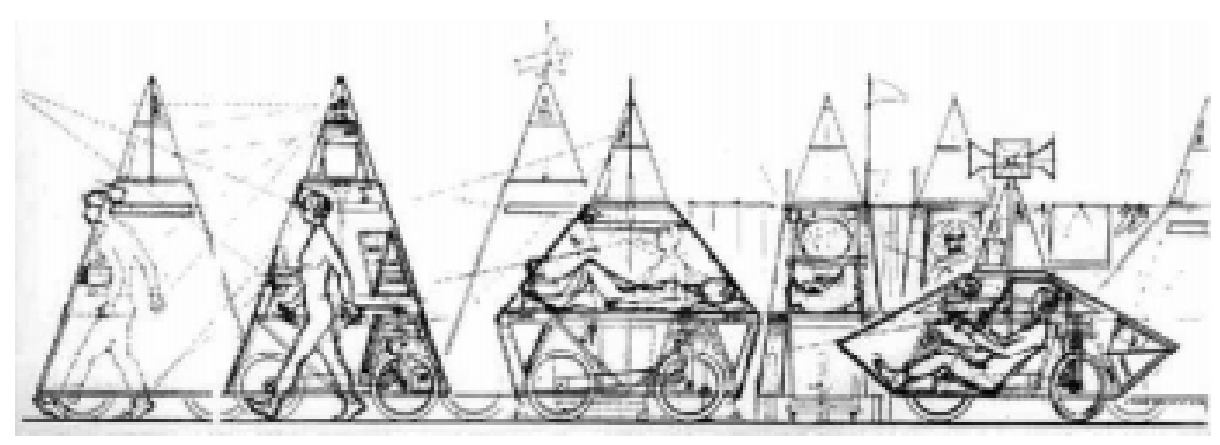

KRZYSZTOF WODICZKO, Projeto de habitação para sem-tetos, 2001

142 Interface-Comunic, Saúde, Educ 9 